\title{
New Horizons
}

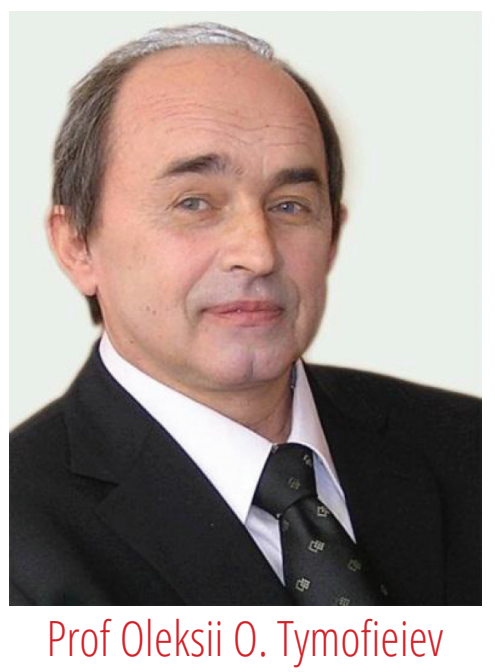

Dear readers,

You are holding in your hands or reading online the first issue of a completely new journal. Treatment of any oral or maxillofacial pathology is not performed without modern diagnostics. CBCT, MDCT, MRI, ultrasound, 3D printing, 3D planning of surgeries and other technologies have become a part of the everyday practice of general practice dentists, periodontists, oral and maxillofacial surgeons, oncologists, and radiologists. Before us are opened up completely new horizons that we need to explore with the maximum benefit for our patients and ourselves.

The President's decision on the adoption of a year 2016 an a year of the English language in Ukraine is dictated by the requirements of the modernity. English opens the door to the whole world of science, conferences, places dating, it gives opportunity to demonstrate our results around the world, to develop joint projects and to increase the profitability of your practice. Therefore we continue that initiative in 2017 with the Journal of Diagnostics and Treatment of Oral and Maxillofacial Pathology, which became the first publication dedicated to maxillofacial pathology in post-Soviet states. The editorial board of the journal includes leading experts from all over the world. With this approach and cooperation with the world, we will all win.

Please enjoy our first issue!

Prof Oleksii O. Tymofieiev

Editor-in-Chief 